Research Article

\title{
Monitoring and Analysis of Stress Distribution of the Interaction between Rock and Backfill and the Influence of Geometric Features of the Backfill Boundary
}

\author{
Rong Lu $\mathbb{D}^{1,2}$ Fengshan Ma $\mathbb{D}^{1},{ }^{2}$ Jie Zhao, ${ }^{1}$ Jianbo Wang, ${ }^{1}$ Guilin Li, ${ }^{1}$ and Bing Dai ${ }^{3}$ \\ ${ }^{1}$ Deep Mining Laboratory Subsidiary of Shandong Gold Mining Technology Co Ltd., Jinan, China \\ ${ }^{2}$ Key Laboratory of Shale Gas and Geoengineering, Institute of Geology and Geophysics, Chinese Academy of Science, \\ Beijing, China \\ ${ }^{3}$ Nuclear Resource Engineering College, University of South China, Hengyang, China
}

Correspondence should be addressed to Fengshan Ma; fsma@mail.iggcas.ac.cn

Received 3 December 2020; Accepted 16 July 2021; Published 5 August 2021

Academic Editor: Yingchun Li

Copyright $\odot 2021$ Rong Lu et al. This is an open access article distributed under the Creative Commons Attribution License, which permits unrestricted use, distribution, and reproduction in any medium, provided the original work is properly cited.

\begin{abstract}
Backfill mining methods are widely used in metal mines. The boundary part of the backfill has a direct effect on the local stability in mining engineering. The distribution of stress on the boundary part of the backfill and surrounding rock had their own features. To study the characteristics of stress distribution of backfill and surrounding rock on the boundary part, we conducted a field investigation, field monitoring, and numerical simulation. According to the underground monitoring, the overall characteristics of the boundary part of the backfill were that the accumulated horizontal stress was larger than the accumulated vertical stress on the deep sublevel and the accumulated horizontal stress was smaller on the shallow sublevel. On the contact zone (i.e., the boundary part), the stress of the surrounding rock was larger than the stress of the backfill. Combined with the numerical model analysis, we determined that the geometric features of the backfill boundary had an influence on the stress distribution of stress. The multistep boundary helped the integrity of the contact zone and local stability in deep mining.
\end{abstract}

\section{Introduction}

Backfill mining method was first introduced to the mining engineering in the 1970s. Since then, the cemented paste backfill has been increasingly and widely used in many underground mines [1-4]. The backfill has played a significant role in bearing mining pressure, controlling rock deformation, and increasing stope stability. The backfill provides a stable working platform for miners and reduces open space that potentially could be filled with surrounding rock in the event of a collapse. Mechanical stability is one of the key criteria of the backfill structure [5-10]. The backfill has become a practice in mining operations around the world and can play a significant role in overall mining operation $[11,12]$. Backfilling processes return much of the waste material to the underground mine. At the same time, it can be used as a structural element that participates in ground support, as well as improving local and regional stability [13].

The mechanical failure of backfill structures not only jeopardizes mining production but also greatly threatens the safety of workers underground and has substantial financial ramifications for the mine [14-16].

With geographically widespread applications around the world and various mine depths, the mechanical behavior of backfill structures has been researched. Many previous studies on concrete have drawn conclusions about the influence of temperature, material ratio, and curing time [10, 17-19]. In addition, the mechanical behavior of backfill has received increasing attention. Chongchong et al. developed a constitutive modeling of backfill by a data-mining approach [20]. Cihangir et al. investigated the influence of activator type, concentration, and slag composition of the mechanical stability of backfill [21]. Qi et al. proposed an 
artificial intelligence-based model to predict the unconfined compression strength of backfill [22].

It is important, however, to recognize and account for differences between field and laboratory samples of backfill to properly interpret laboratory results. In the process of filling in some large mines, backfilling strategies have varied between mine sites depending on the backfill pressures and barricade strengths [23-25]. Researchers have proposed that there two factors influencing backfill mechanical behavior. The first factor is that the filling process is performed as quickly as possible without compromising the containment barricade erected at stope draw-points. Barricade failure has influenced the progress of mining engineering. The second factor is the self-supporting of backfill, which has influenced the stability and safety of mining operations [26-28]. Le Roux et al. demonstrated that backfill shear strength for in situ backfill was 50\%-80\% higher than laboratory-prepared samples [29].

The stability of backfill structures is a function of many factors, such as the mechanical properties of backfill as well as the interface shear stress between the backfill and rock mass surrounding or adjacent the backfill structures. With an increase in mining depth, the volume of backfill has increased in recent decades. The stability of the large backfill is gaining attention in many deep-mining sites. Some studies also have conducted the backfill mechanical behavior [30-34]. However, the interaction and local stability of interface of backfill and surrounding rock have been overlooked for many years. In the Jinchuan Nickel Mine, deformation of a large volume of backfill has led to rock movement and ground subsidence [35]. The mechanical behavior of the backfill also has been studied [36]. In the study area, the local stability of the backfill in the boundary part has significance for stope mining. In recent years, local failures have occurred in underground mining. Investigations have showed that the geometric feature of the backfill boundary is a major factor affecting the mechanical behavior of the backfill-rock interface. Therefore, the main objective of this paper was to study the effect of different types of boundaries on the mechanical behavior of the backfill-rock contact zone.

\section{Background of Study Area}

In this article, the study area was located in the No. 2 zone of the Jinchuan Nickel Mine. The Jinchuan Nickel Mine, the largest deposit of nickel, is located in the city of Jinchang in northwest of China. The ore deposit is about $6.5 \mathrm{~km}$ long, tens of meters to $570 \mathrm{~m}$ wide, and extends to more than $1000 \mathrm{~m}$ in depth. The strike of the ore body is northwest and dips to the southwest, and the dip angle ranges from $40^{\circ}$ to $70^{\circ}$, as shown in Figure 1(a). The native ore-bearing rocks are divided into four independent fields because of the major faults, as shown in Figure 1(b). The tectonic structures (e.g., faults, joints, and contact fracture zones) produce fragmentation within the host rock, causing poor mechanical stability. The maximum principal stress is horizontal and NE oriented. The maximum principal stress reaches $50 \mathrm{MPa}$ at a depth of $500 \mathrm{~m} \mathrm{[37].} \mathrm{The} \mathrm{intermediate} \mathrm{principal} \mathrm{stress}$ corresponds to the vertical stress of the virgin rock mass while the minimum principal stress is horizontal, acting almost parallel to the strike of ore body.

The mechanized backfill mining technique has been adopted at the Jinchuan Mine. In the mining process, once excavation is finished within an access drift, the void is filled using cement paste before the next access drift is excavated. Mining proceeds from the top to the bottom in a series of horizontal four-meter-high drift slices. Mining panels are approximately $100 \mathrm{~m}$ wide and perpendicular to the strike of the ore body. To increase production, simultaneous mining is carried on two or more sublevels. The annual output of the No. 2 zone of the Jinchuan Nickel Mine is more than four million tons. The volume of backfill is shown in Figure 2. The current mining operation encompasses more than $1000 \mathrm{~m}$ underground. We extended the field investigation and measurement to a sublevel of $1050 \mathrm{~m}$.

\section{Backfill Stress and Deformation Monitoring}

3.1. The Layout of Stress Monitoring Gauges. Backfill is of vital importance in mining. The backfill is a passive support measurement. Tectonic stress is the major influencing factor of stress distribution in backfill. In the study area, the tectonic stress was nearly horizontal, and the horizontal stress coefficient was 1.5 2.0. Roadway deformation underground indicated that the horizontal tectonic stress acted directly on the surrounding rock and then transferred to the backfill through the surrounding rock material. The stress gauges were set on the boundary part area to monitor the stress development and interaction between the surrounding rock and backfill.

In the monitoring operation, we set four stress gauges on each point to measure the backfill horizontal (BH) stress, backfill vertical (BV) stress, surrounding rock horizontal (SH) stress, and surrounding rock vertical (SV) stress (as shown in Figure 3). We analyzed the monitoring results of three points because of data stabilization. The location and marked numbers of these monitoring points are shown in Figure 2.

The monitoring instruments were Model-9200 embedded stress-strain gauge. In these three sublevels, there were 10 group measurement instruments, and a group instrument included four gauges.

3.2. Results of Field Monitoring. The monitoring results as shown in Figure 4 demonstrate the accumulated stress distribution of the backfill in the sublevel at $1100 \mathrm{~m}$ in the parts of exploratory line-12, line-14, and line-16. For these three monitoring points, accumulated horizontal stress was larger than accumulated vertical stress in all parts of the backfill, at same time. Figure 5 shows the accumulated stress distribution of the backfill in the sublevel at $1200 \mathrm{~m}$ located at exploratory line-10 and line-15. The location of the points in the sublevel at $1100 \mathrm{~m}$ was deeper than the location of the points in the sublevel at $1200 \mathrm{~m}$. The characteristics of stress distribution in the deeper part (in the sublevel at $1100 \mathrm{~m}$ ) were different from those in the shallow part (in the sublevel 


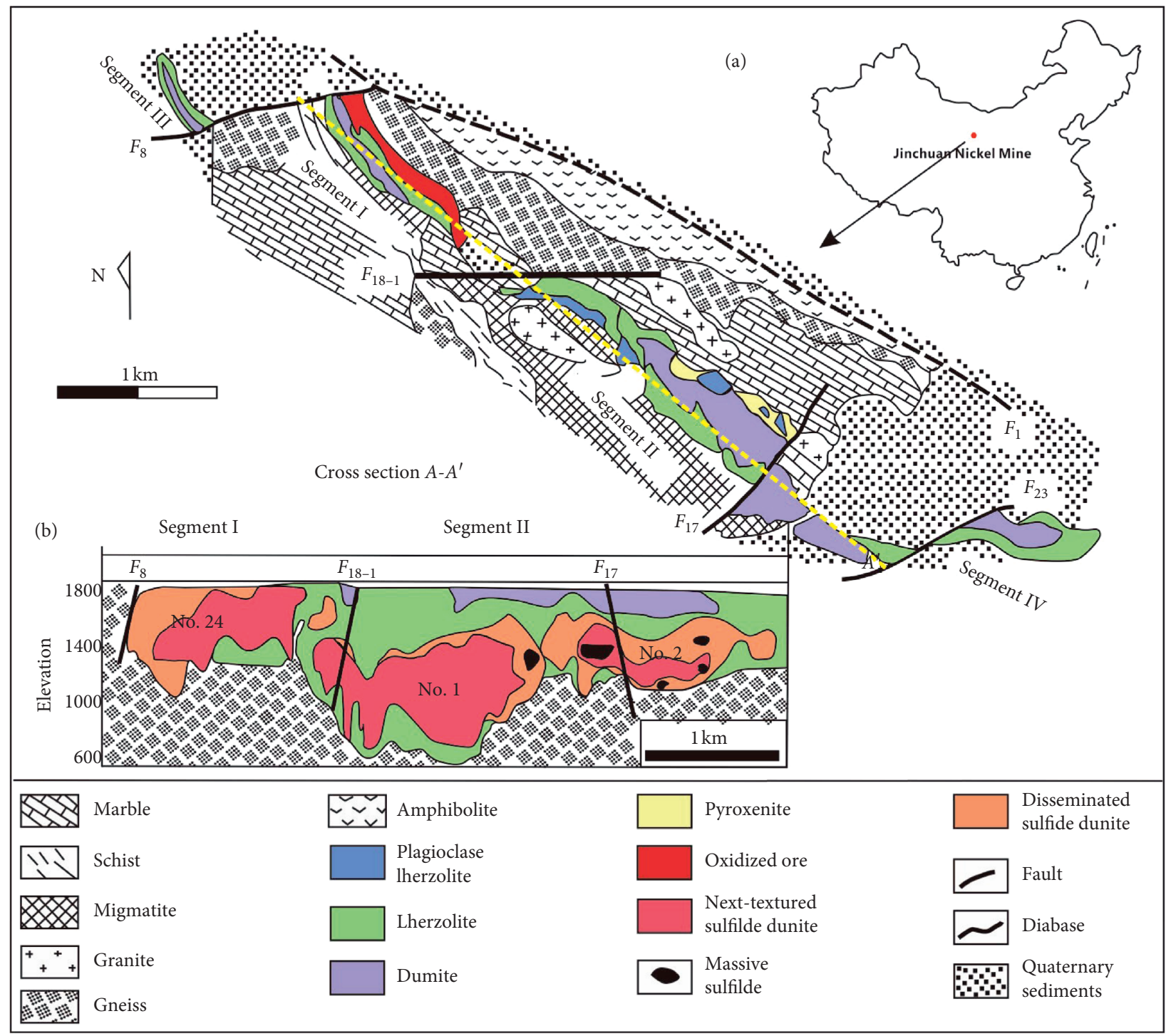

Figure 1: Geological map of the study area: (a) the main tectonic units of the Jinchuan Mine; (b) simplified geological map and a cross section of the Jinchuan Mine.

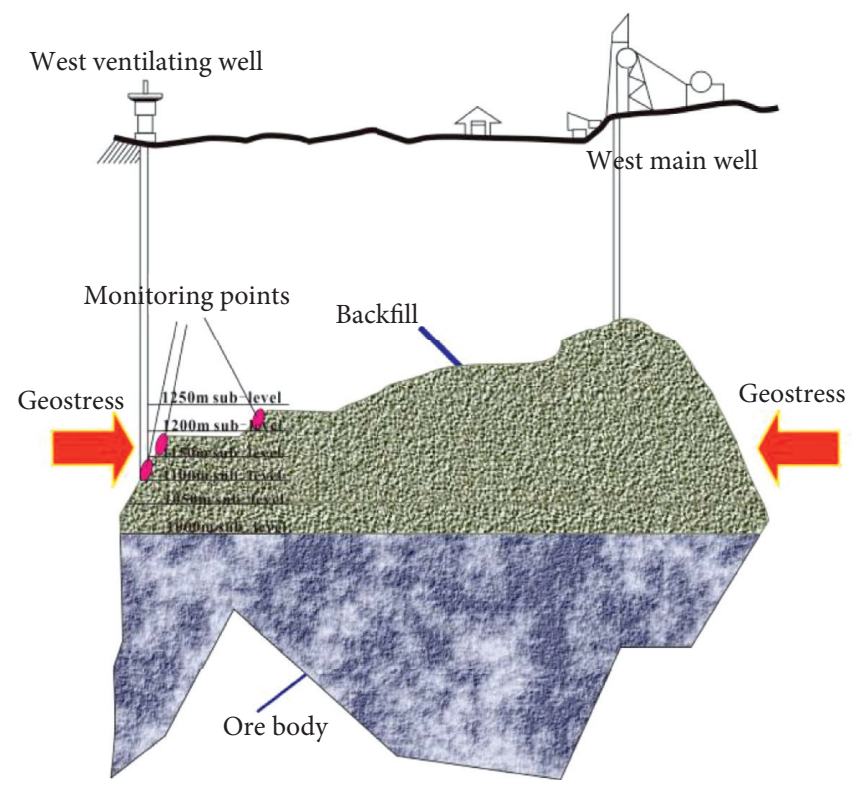

FIgURE 2: The sketch plot of mining operation. 

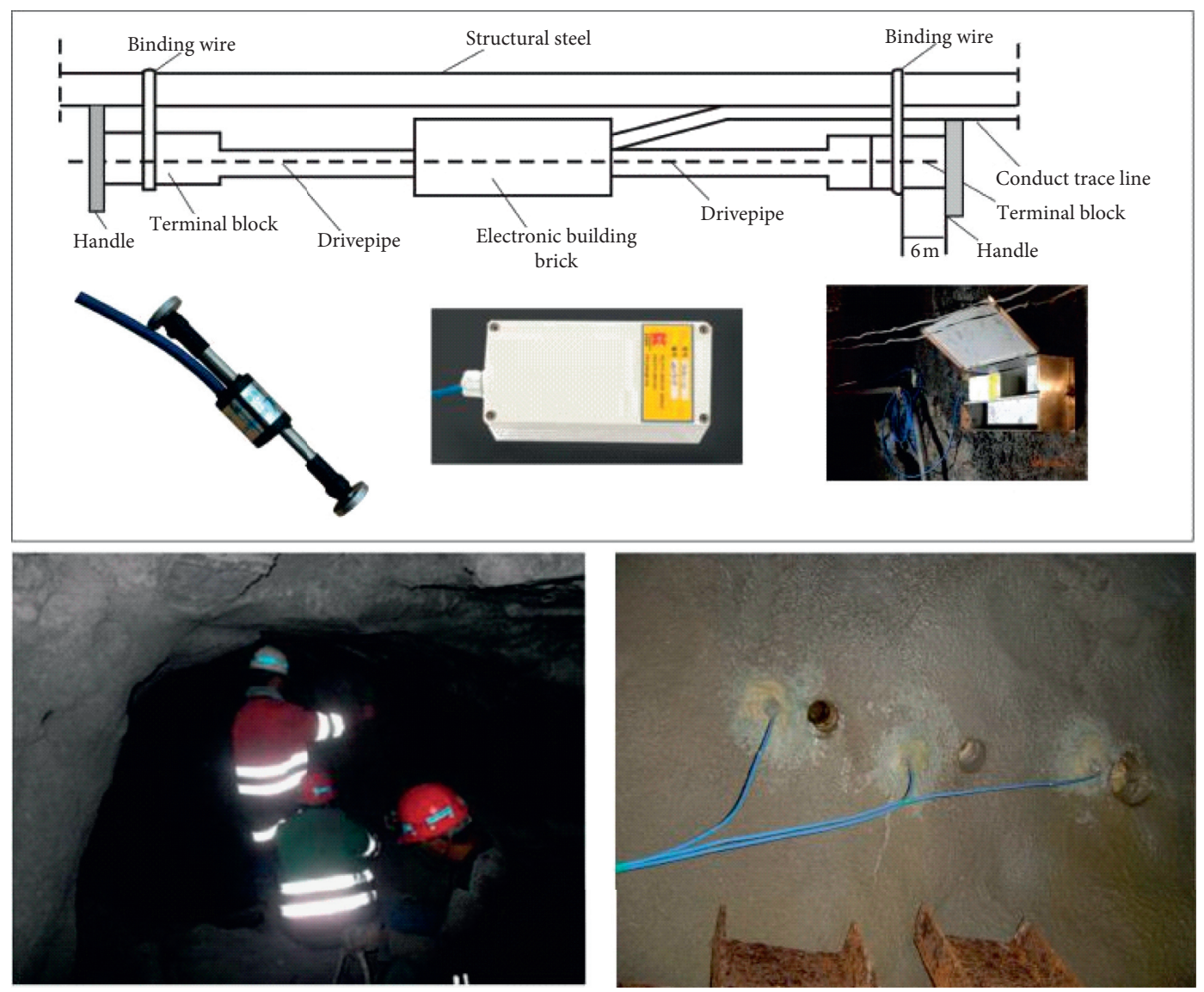

Figure 3: The installation of stress gauges underground.

at $1200 \mathrm{~m}$ ). In the deeper part of the backfill boundary, the accumulated horizontal stress was larger than the accumulated vertical stress. In the shallow part of the backfill boundary, the accumulated vertical stress was larger than the accumulated horizontal stress.

The stress distribution of the surrounding rock and backfill is shown in Figure 6. We also analyzed the results of the sublevel at $1200 \mathrm{~m}$ located exploratory line-10. On the contact zone of the surrounding rock and backfill (boundary part of backfill), the horizontal stress and vertical accumulated stress of the surrounding rock were both larger than those of the backfill.

3.3. The Influence of Geometric Features on the Stress Distribution. The profile of the backfill boundary had distinct features. The geometric feature was irregular and steplike. For each sublevel mining height, we divided the boundary into three types according to its geometric features: linear boundary single-step boundary and multistep boundary. Figure 7 shows the change rate of stress at the same depth (the sublevel at $1100 \mathrm{~m}$ ). Figure 7 shows that the geometric boundary of monitoring point FP-1 (at $1100 \mathrm{~m}$ located exploratory line-14) was linear and the geometric boundary of monitoring point FP-2 (at $1100 \mathrm{~m}$ located exploratory line-16) was a multistep. And the geometric boundary of monitoring point FP-3 (at $1200 \mathrm{~m}$ located exploratory line-16) was single step. Figure 8 shows that the change rate of the horizontal and vertical stress on the multistep boundary was larger than the change rate on the linear boundary. The curve trends of the vertical stress in the linear and multistep boundaries were similar (as shown in Figure 8(b)).

The curve trends of horizontal stress in linear and multistep boundaries were different (as shown Figure 8(a)). The change rate of horizontal stress at point FP-3 was smaller than that at point FP-4 and fluctuated in a stable manner (nearly $0.2 \mathrm{MPa}$ ). Initially, the change rate of horizontal stress at point $\mathrm{FP}-3$ reached $0.9 \mathrm{MPa}$ but then decreased obviously.

FP-3 and FP-4 were located on the same exploratory line. FP-3 was located at the deeper part and had a multistep boundary, and FP-4 was located at the shallow part (as shown in Figure 8(b)) and had a single-step boundary. The vertical stress change was influenced directly by depth. In the shallow part, the vertical stress remained in the same direction. In the deeper part, the vertical stress direction changed. The multistep boundary monitoring point had greater stress than the single-step boundary point (as shown in Figure 9). The change rate of the horizontal stress at point FP-3 was larger than that at point FP-4. On the basis of this analysis, we identified the geometric feature of boundary influence on the stress distribution on the contact zone of the backfill and surrounding rock. The single-step boundary was 


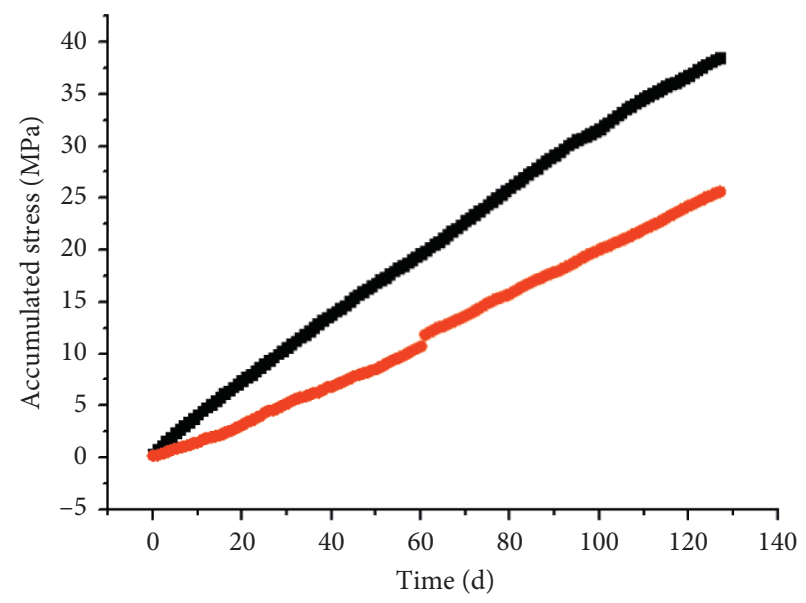

$\rightarrow$ - BH-1100m-12\# $\rightarrow$ BV-1100m-12\#

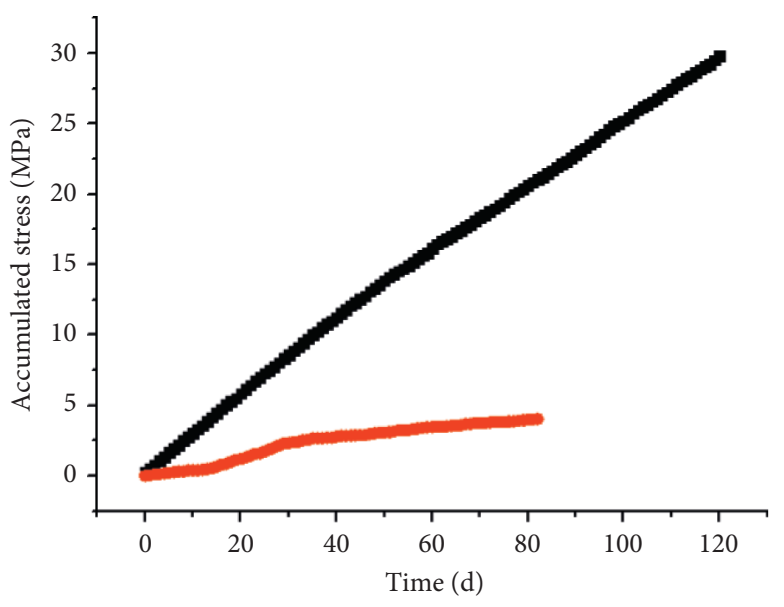

- - BH-1100m-14\# $\longrightarrow$ BV-1100m-14\#

(a)

(b)

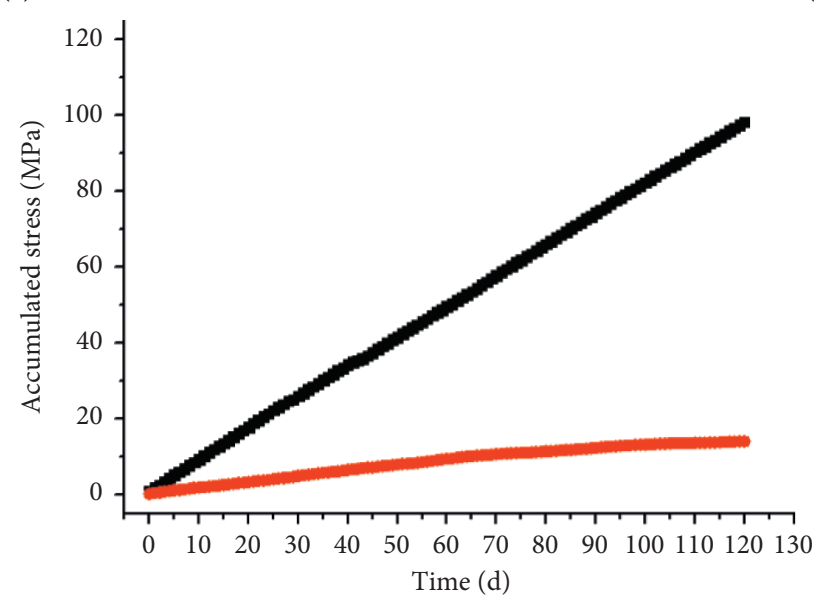

- $\mathrm{BH}-1100 \mathrm{~m}-16 \#$

$\rightarrow$ BV-1100m-16\#

(c)

FIgURE 4: The curves of backfill accumulated horizontal stress and accumulated vertical stress in $1100 \mathrm{~m}$ sublevel: (a) the curve of point in exploratory line-12; (b) the curve of point in exploratory line-14; (c) the curve of point in exploratory line-16.

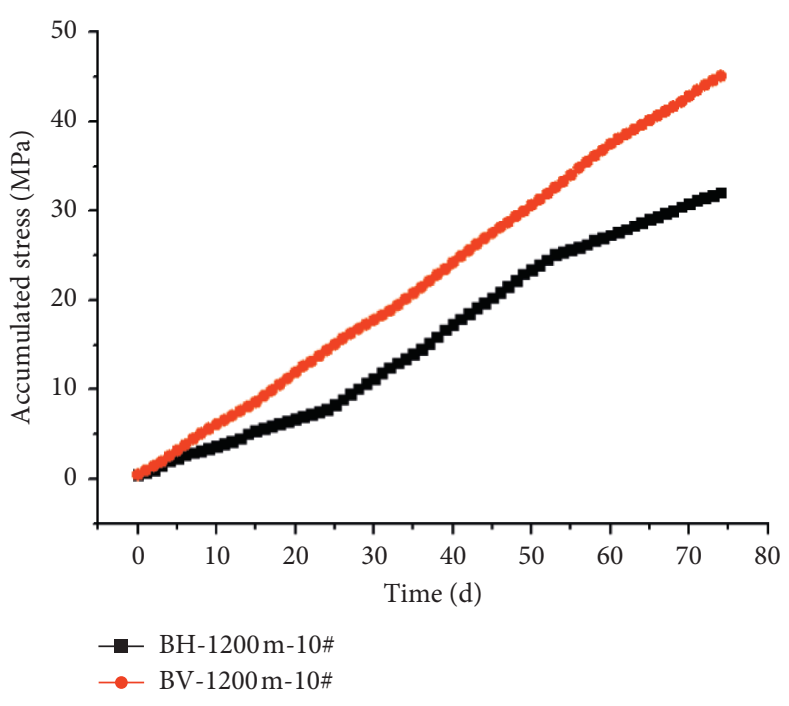

(a)

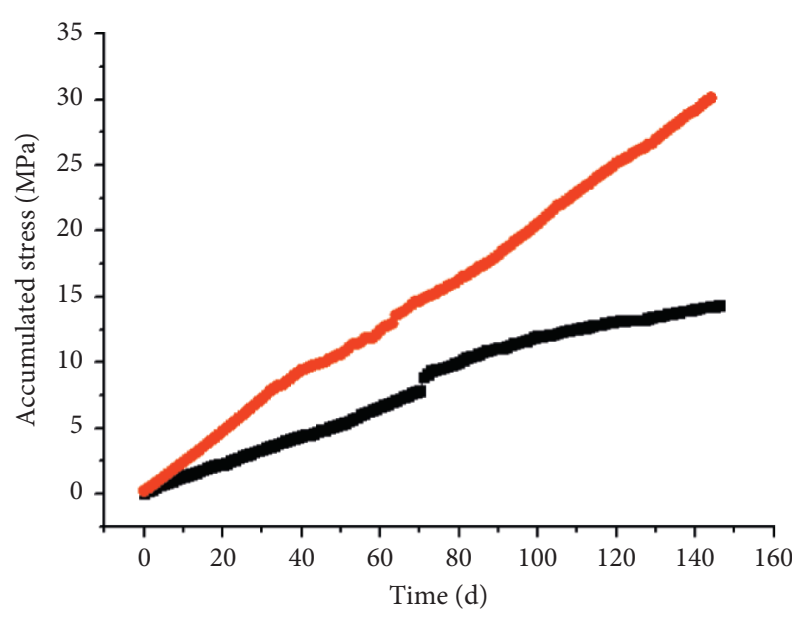

- BH-1200m-15\#

- BV- $1200 \mathrm{~m}-15 \#$

Figure 5: The curves of backfill accumulated horizontal stress and accumulated vertical stress in $1200 \mathrm{~m}$ sublevel: (a) the curve of point in exploratory line-10; (b) the curve of point in exploratory line- 15. 


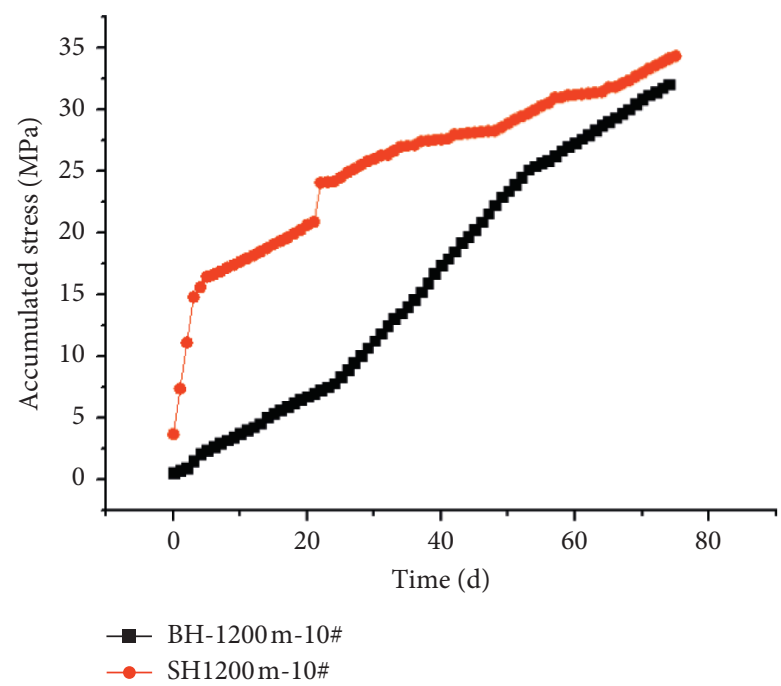

(a)

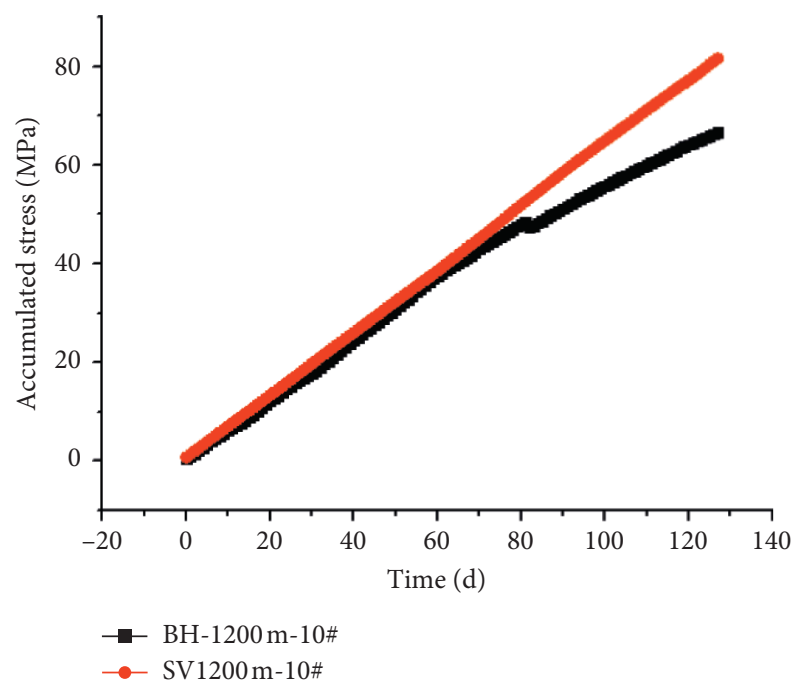

(b)

FIGURE 6: The curves of backfill accumulated stress of backfill and surrounding rock at point exploratory line-10 of the sublevel of 1200 : (a) the curve of horizontal at of backfill and surrounding rock; (b) the curve of vertical of backfill and surrounding rock.

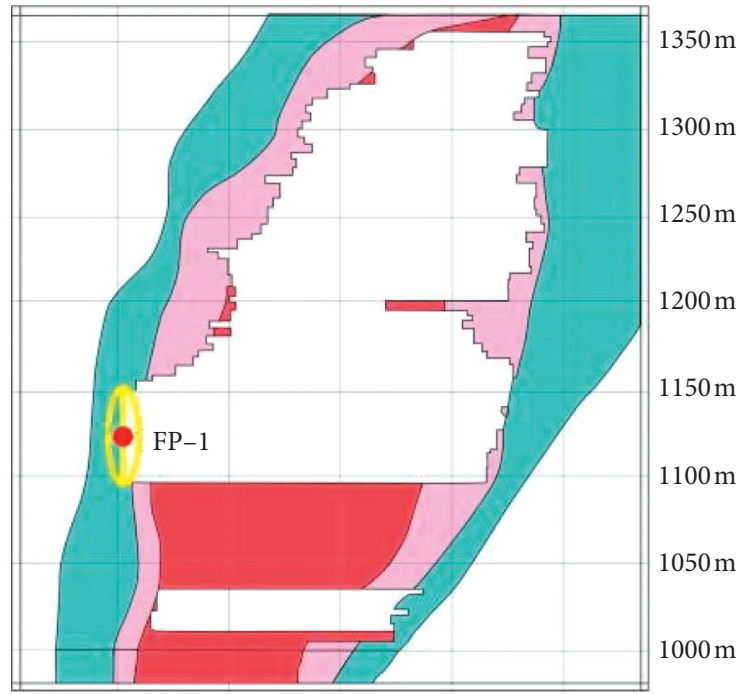

(a)

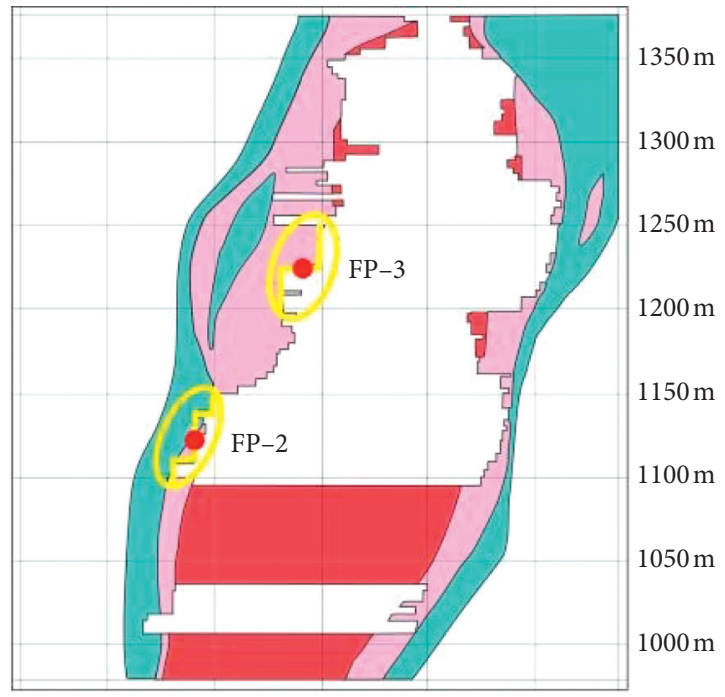

(b)

FiguRE 7: The boundary geometric features at the monitoring points: (a) the profile drawn of exploratory line-14 at $1100 \mathrm{~m}$ sublevel; (b) the profile drawn of exploratory line-16 at $1100 \mathrm{~m}$ sublevel.

more complex than the linear boundary, and multistep boundary was more complex than the single-step boundary. The degree of complexity had an effect on the stress transference and on the interaction between the surrounding rock and the backfill on the contact zone, which influenced the local stability of the backfill boundary.

\section{Numerical Simulation}

According to field monitoring, our preliminary conclusion was that the geometric characteristic of the boundary influenced the distribution of stress on the contact zone of the backfill-surrounding rock. We built the numerical models to simulate local stress distribution of the contact zone between the backfill-surrounding rock. The three types of backfill boundaries were linear boundary, single-step boundary, and multistep boundary, as shown in Figure 10. The specific length of single-step boundary is $7 \mathrm{~m}$, and the length of multistep boundary is $5 \mathrm{~m}$. The lengths were set up according to the actual situation.

According to the field backfill boundary size, we set the model height to $20 \mathrm{~m}$. We studied the backfill and surrounding rock on the hanging side. In the numerical models, the material on the left was surrounding rock and the material on the right was backfill. The parameters of the surrounding rock material and backfill material are shown in 


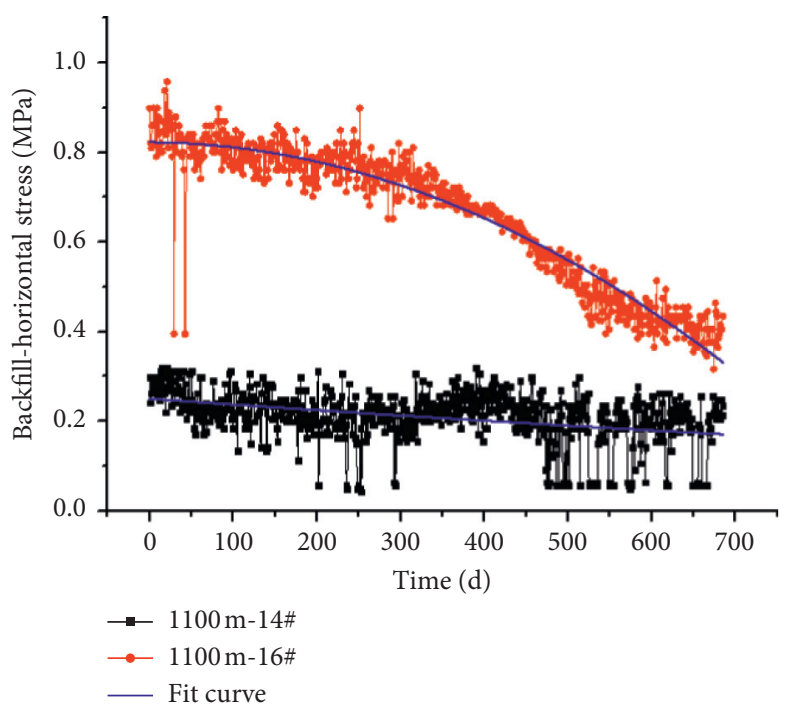

(a)

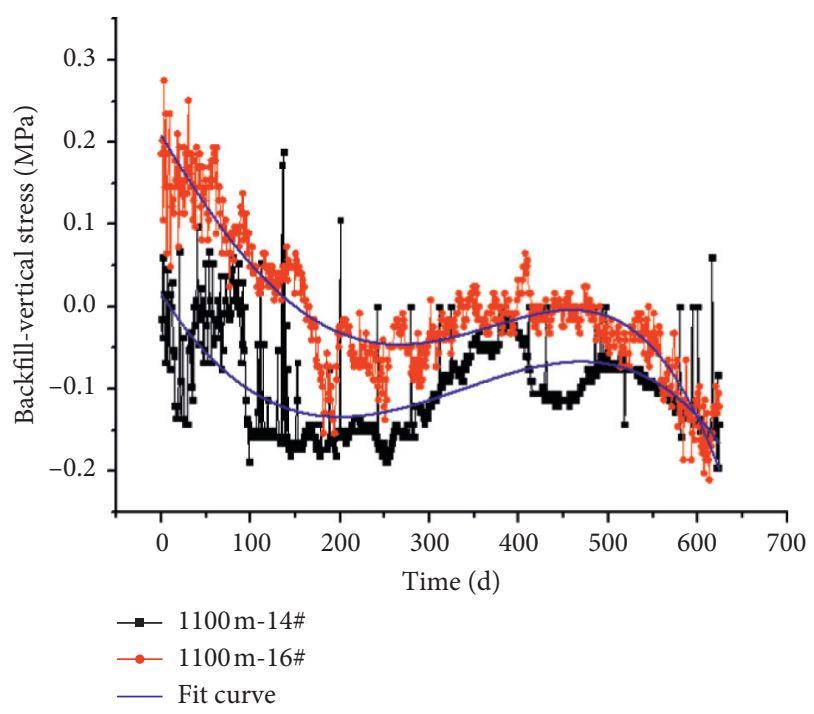

(b)

FiguRE 8: The change rate of stress on the same depth (the sublevel of $1100 \mathrm{~m}$ ): (a) the change rate of horizontal stress; (b) the change rate of vertical stress.

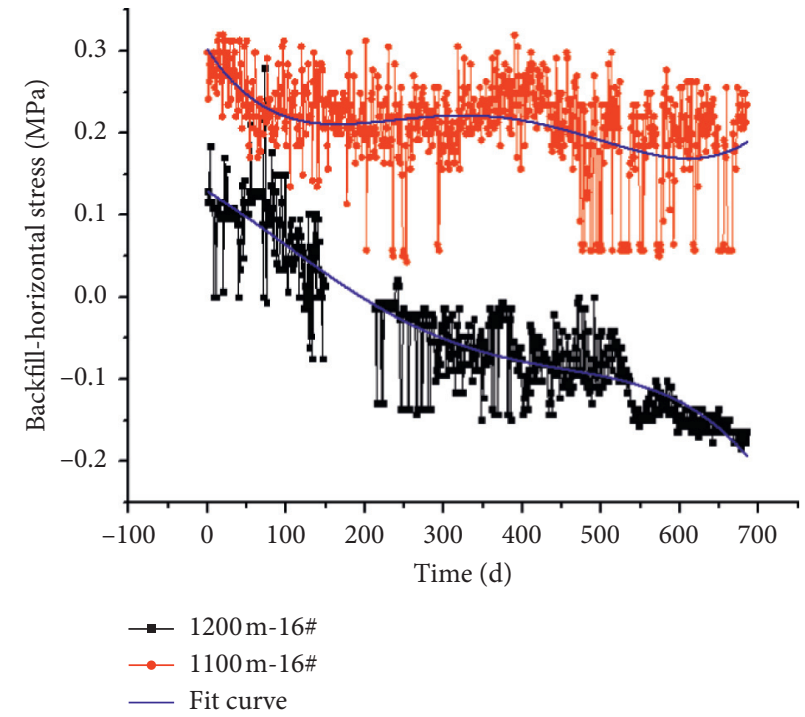

(a)

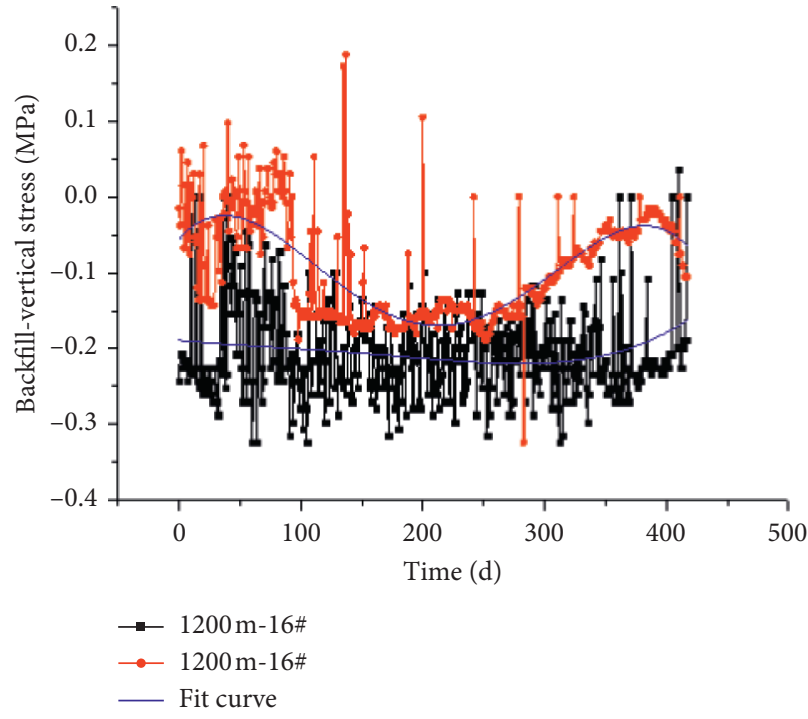

(b)

FIGURE 9: The change rate of stress on the different depths (the sublevel of $1100 \mathrm{~m}$ and $1200 \mathrm{~m}$ ): (a) the change rate of horizontal stress; (b) the change rate of vertical stress.

Table 1 . We set the vertical stress according to the overburden pressure, and the horizontal stress coefficient was 1.5. We set the vertical stress on the top of the model and set the horizontal stress only on the left side of the model. The horizontal stress was applied only on the surrounding rock and was transferred to the backfill by the rock material particles. The numerical simulation model was built by a discrete element software, $\mathrm{PFC}^{-2 \mathrm{D}}$.
4.1. Numerical Models Validation. Firstly, these models need to be validated according to field monitoring results. Figure 11 demonstrates the stress distribution of top and bottom parts of three numerical models. Figures 11(a)-11(f) show the horizontal and vertical stress boundary backfill of linear, single-step, and multistep models, respectively. As the multistep boundary model example, Figure 11(e) represents stress distribution of the shallow part of the model and 


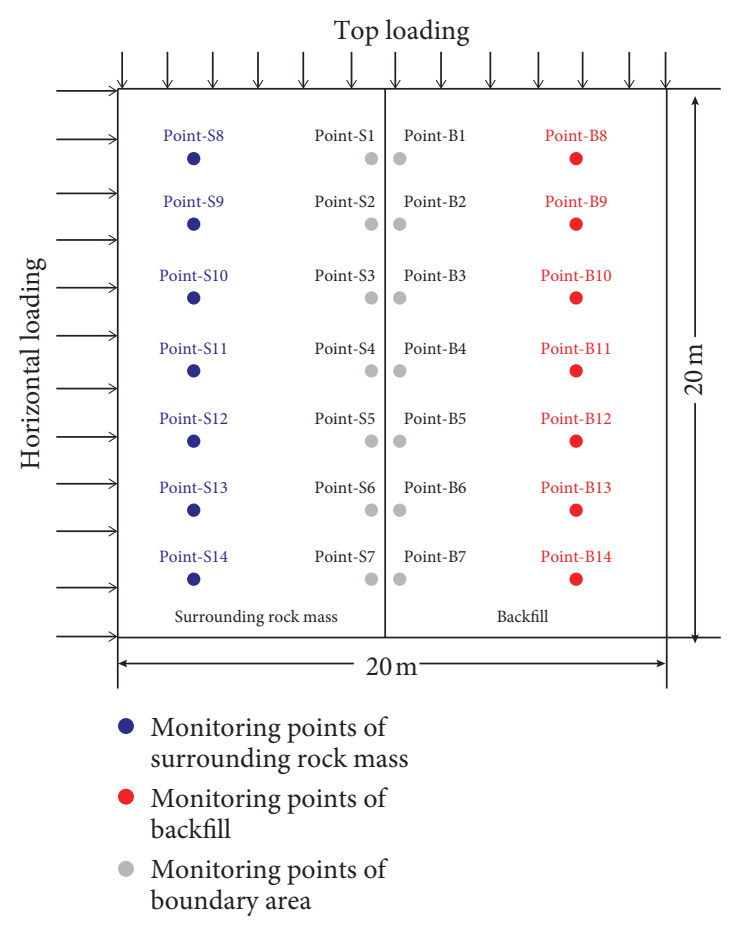

(a)

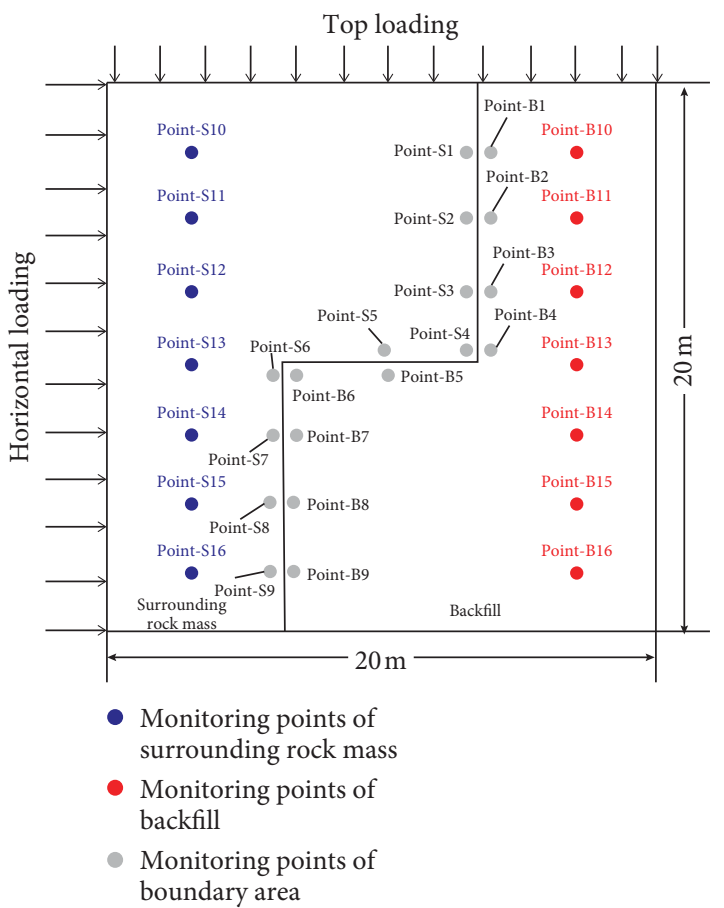

(b)

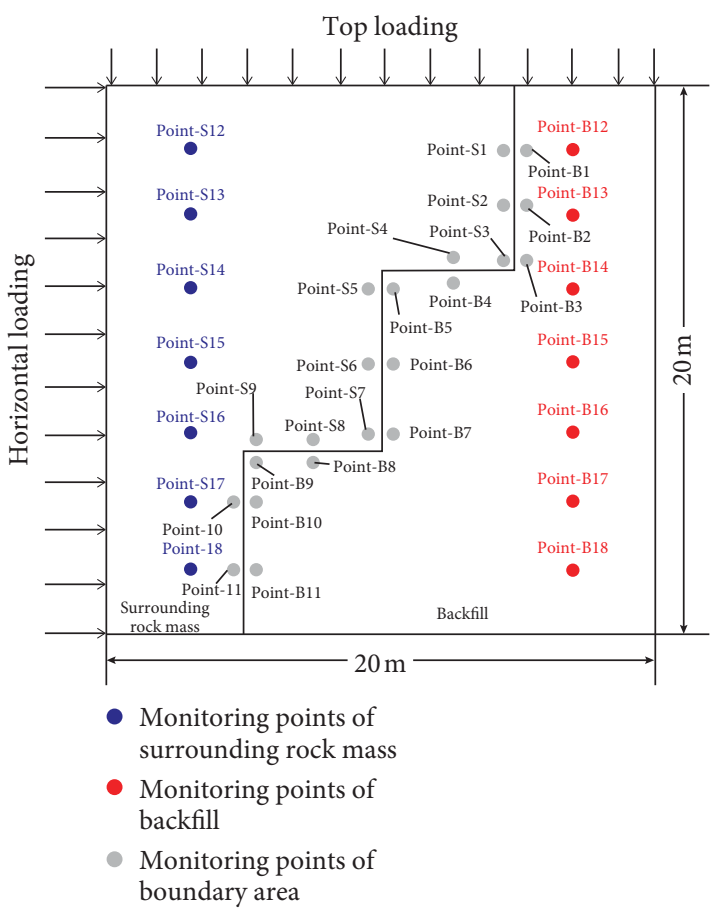

(c)

FIgURE 10: The profile of numerical models.

Figure 11(f) represents stress distribution the deep part of the model. In shallow part, the vertical stress was larger than the horizontal stress. And in deep part, the horizontal stress was larger than the vertical stress. The other two models have the same characteristics. These features of stress distribution were consistent with the results of field monitoring. Therefore, the numerical models were verified.
4.2. Strength Analysis of Numerical Models. The overall strength of models is shown in Figure 12(a). The strength of the contact zone model with the linear boundary was $56.87 \mathrm{MPa}$, the strength of the contact zone model with the single-step boundary was $39.58 \mathrm{MPa}$, and the strength of the contact zone model with the multistep boundary was 39.90 MPa. The strength of the contact zone model with the 
TABle 1: Parameters of the surrounding rock and backfill material.

\begin{tabular}{lcr}
\hline Parameters & Surrounding rock material & Backfill material \\
\hline Elastic modulus & $1^{*} 10^{9} \mathrm{MPa}$ & $9^{*} 10^{7} \mathrm{MPa}$ \\
Poisson ratio & 0.24 & 0.23 \\
Friction angle & $33^{\circ}$ & $32^{\circ}$ \\
Cohesion & $15 \mathrm{MPa}$ & $5 \mathrm{MPa}$ \\
\hline
\end{tabular}

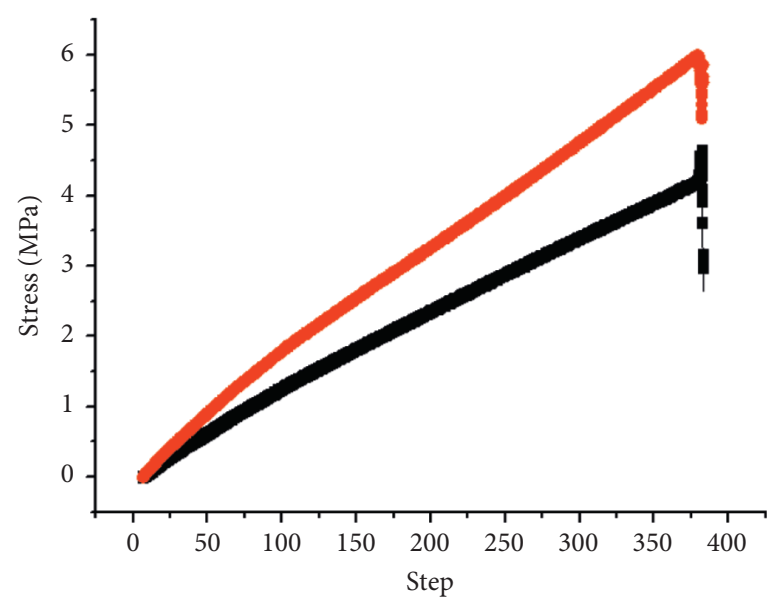

$\rightarrow$ Linear-boundary-top-BH

$\rightarrow$ Linear-boundary-top-BV

(a)

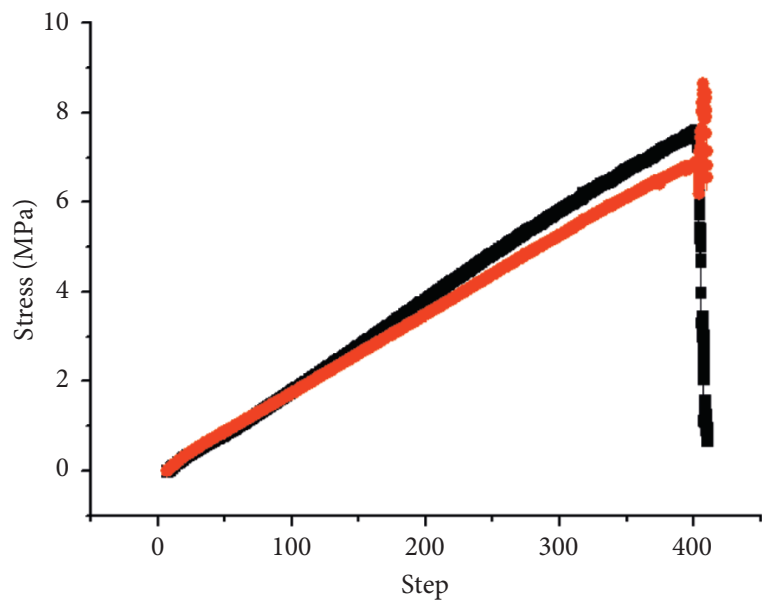

- Single boundary-top-BH

$\longrightarrow$ Single boundary-top-BV

(c)

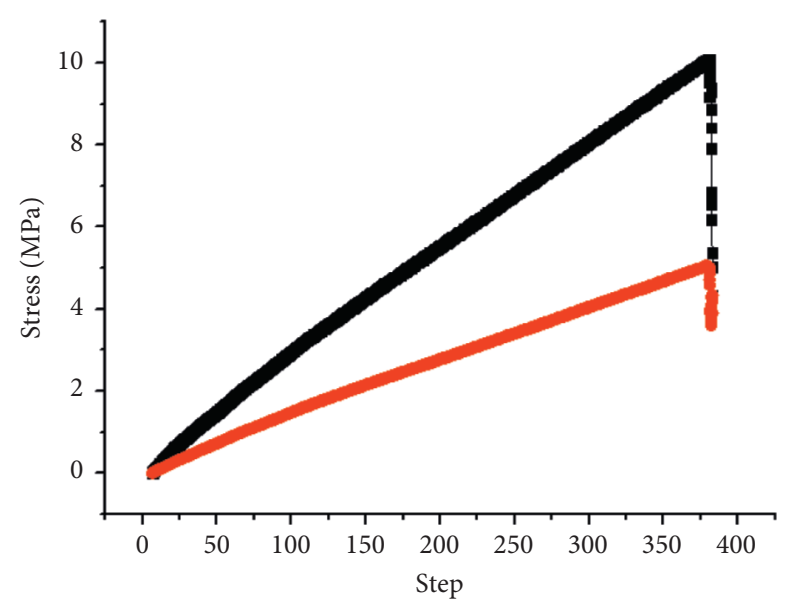

$\rightarrow$ Linear-boundary-bottom-BH

$\rightarrow$ Linear-boundary-bottom-BV

(b)

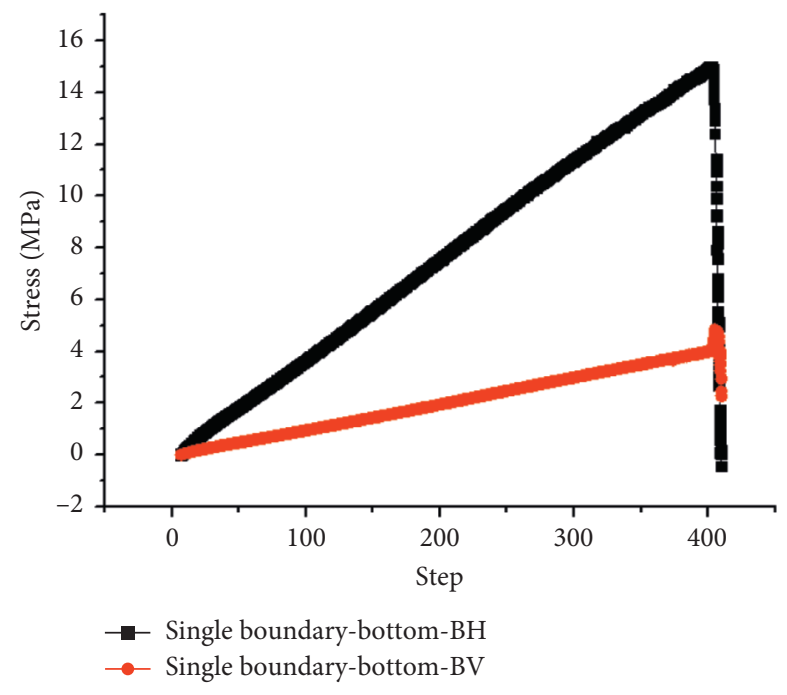

(d)

Figure 11: Continued. 


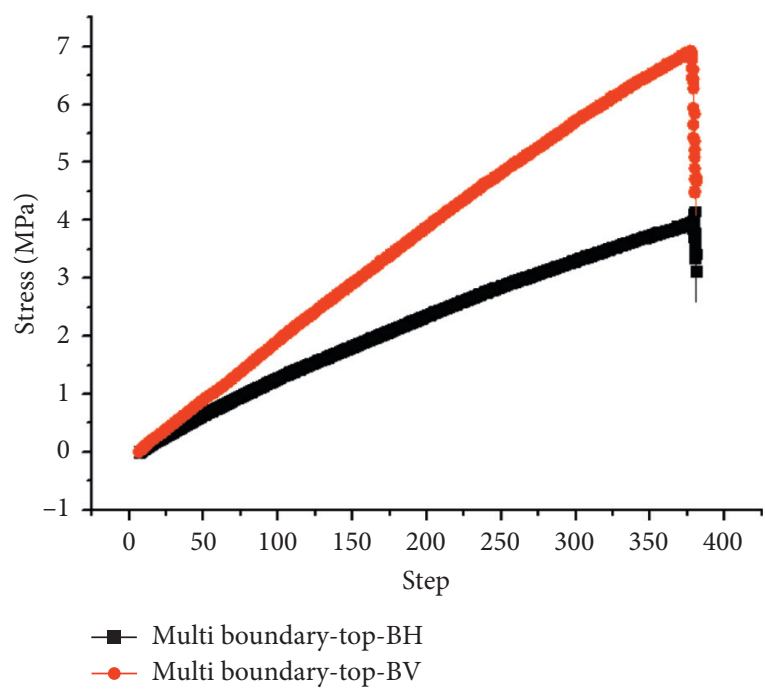

(e)

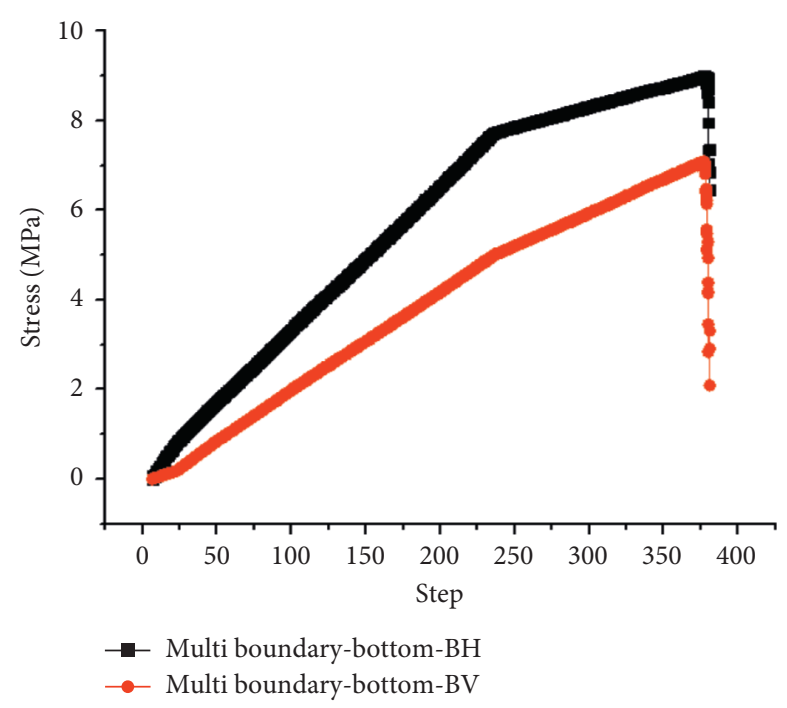

(f)

FIGURE 11: Horizontal and vertical stress distribution of three numerical models: (a) stress distribution of the top part of the linear boundary model; (b) stress distribution of the bottom part of the linear boundary model; (c) stress distribution of the top part of the single-step boundary model; (d) stress distribution of the bottom part of the single-step boundary mode; (e) stress distribution of the top part of the multistep boundary mode; (f) stress distribution of the bottom part of the multistep boundary model.

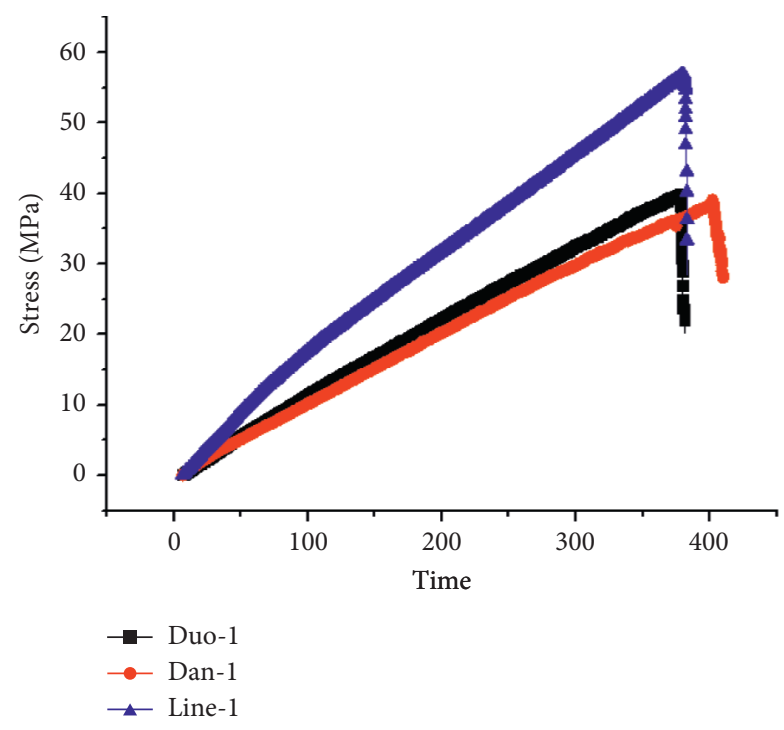

(a)

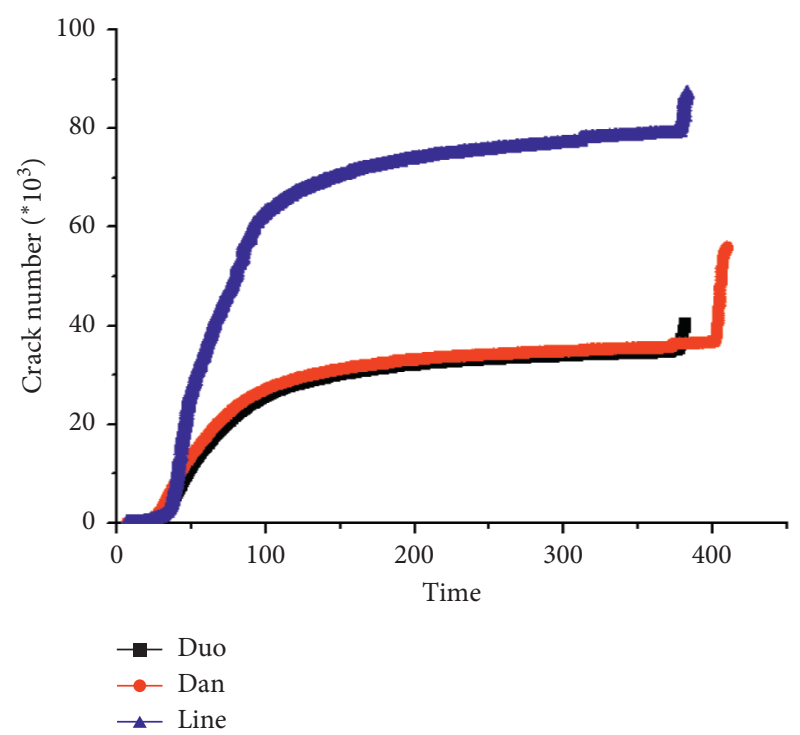

(b)

Figure 12: (a) The strength of three models; (b) the crack numbers of three models.

linear boundary was more than the other two models. Figure 12(b) shows the crack development in these three models. Cracks developed sharply during prepeak strength. The cracks of the model with a linear boundary developed more significantly than in the other two models.

The interfacial properties between the backfill and rock mass play a significant rock in the transmission of stress from the rock to backfill. Regardless of its strength, the backfill represents a soft material in comparison to the mechanical properties of the adjacent or surrounding rock.
On interface between the backfill and rock mass, the stress transferred from surrounding rock to the backfill, especially with the horizontal stress. Figure 13 shows the vectors of the particle movement in the three models, which indicated the stress transfer. The horizontal stress was applied to the surrounding rock and then was transferred to the backfill. The stress vectors changed along the backfill boundary. The degree to which the stress vectors changed was different in these three models. In some underground hard rock mines, backfill helps preventing caving and roof falls and reduces 


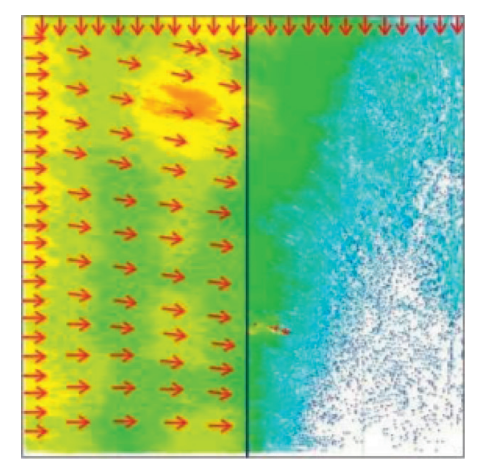

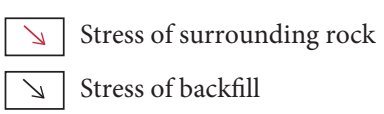

(a)

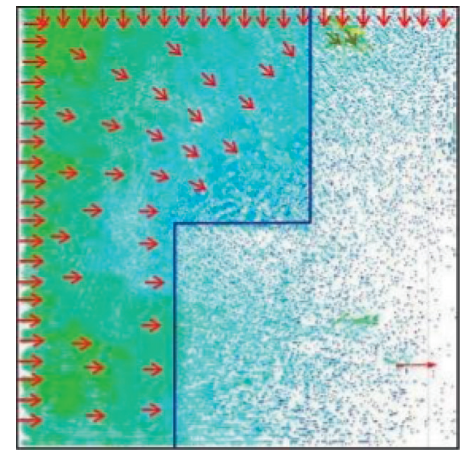

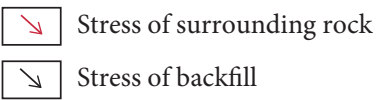

(d)

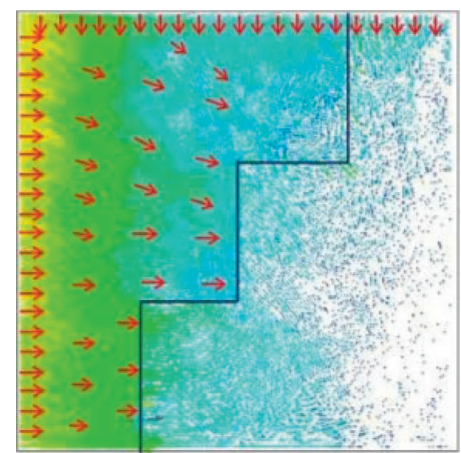

\begin{tabular}{|l|}
$\searrow \searrow$ Stress of surrounding rock \\
\hline$\searrow$ Stress of backfill
\end{tabular}

(g)

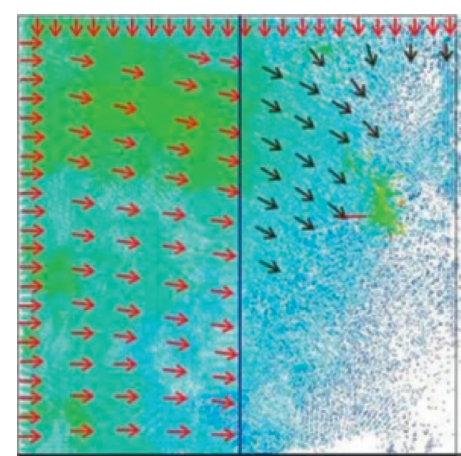

\begin{tabular}{|l}
\hline$\searrow$ Stress of surrounding rock \\
$\square$ Stress of backfill
\end{tabular}

(b)

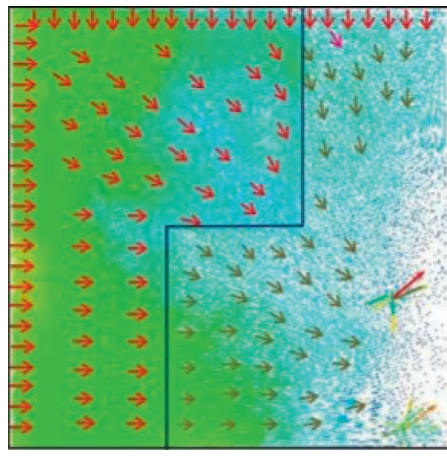

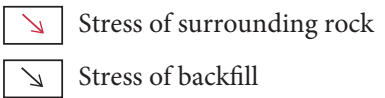

(e)

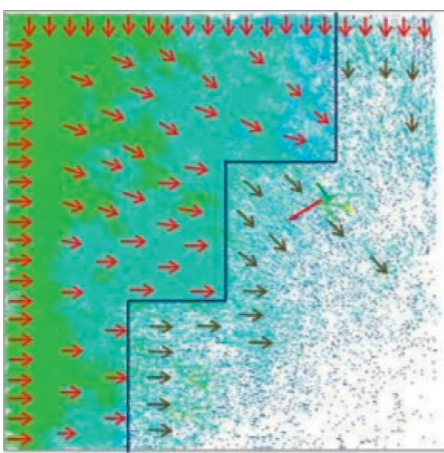

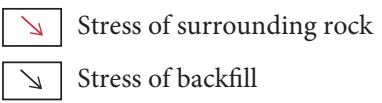

(h)

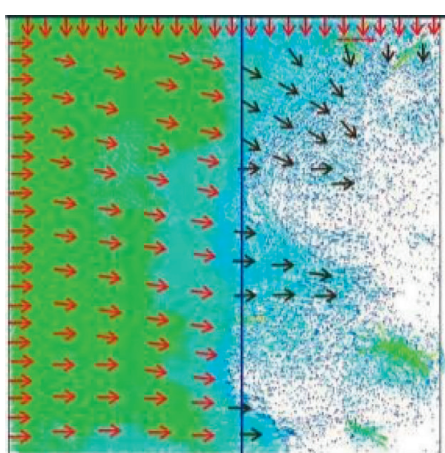

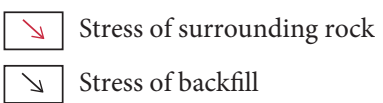

(c)

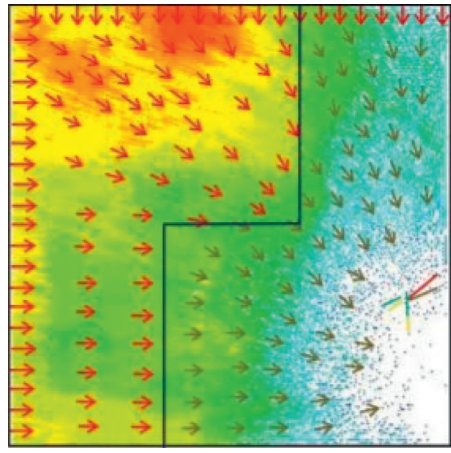

$\searrow$ Stress of surrounding rock

$\searrow$ Stress of backfill

(f)

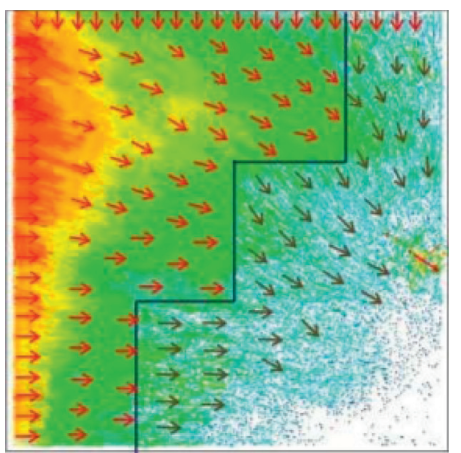

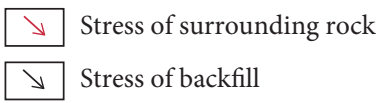

(i)

FIgURe 13: The stress vectors of three models: $(\mathrm{a} \sim \mathrm{c})$ the stress vectors development of the linear boundary model; $(\mathrm{d} \sim \mathrm{f})$ the stress vectors development of the single-step boundary model; $(\mathrm{g} \sim \mathrm{i})$ the stress vectors development of the multistep boundary model.

vertical stress and increases horizontal stress distribution within fill mass $[38,39]$. Figure 12 shows the external stress action on the contact zone. The change in the direction of the stress vectors was the largest in the multistep boundary model, and the change in the direction of the stress vectors was the smallest in the linear boundary model. Therefore, we determined that the complexity of the geometric boundary contributed to the change in stress direction.

\subsection{The Stress Difference between Backfill and the Surrounding} Rock on the Contact Zone in Three Numerical Models. 


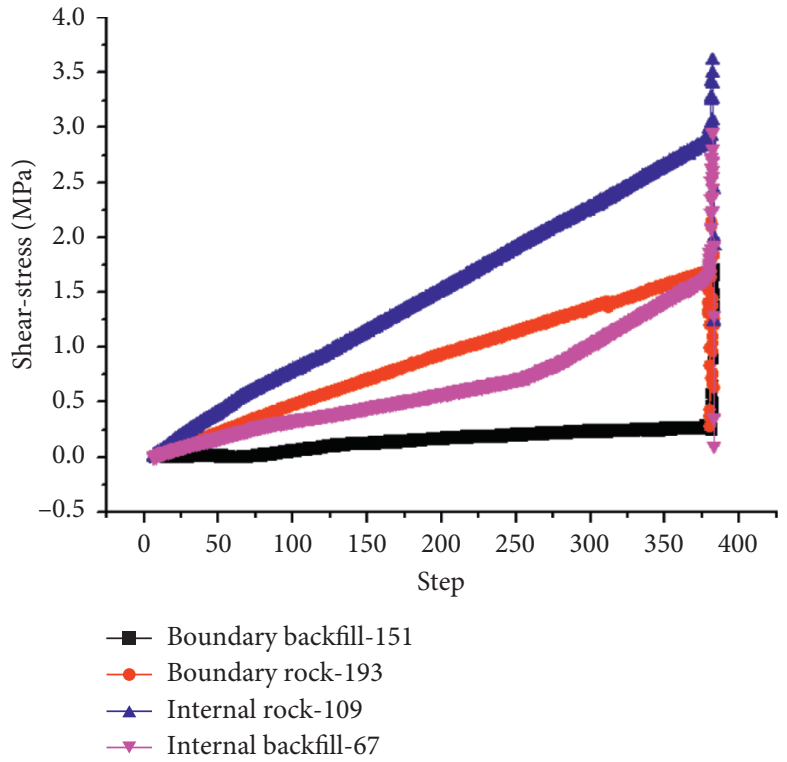

(a)

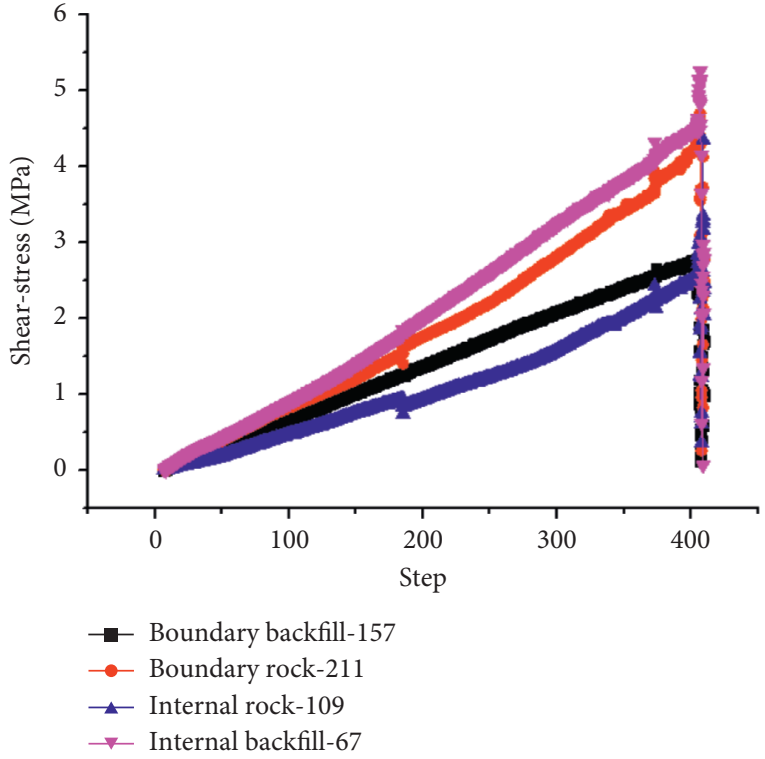

(b)

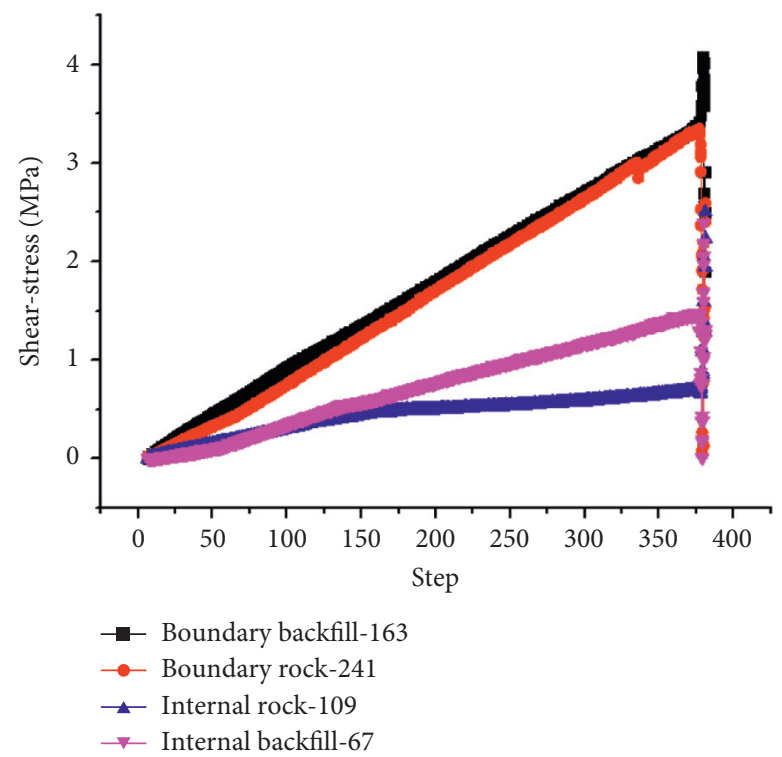

(c)

FIGURE 14: The shear stress of backfill and surrounding rock on the boundary part: (a) the shear stress of the linear boundary model; (b) the shear stress of the single-step boundary model; (c) the shear stress of the multistep boundary model.

The external stress acted on the contacted zone which leads to the shear stress on the backfill and the surrounding rock at this zone. In some cases, the large-scale roughness of the stope walls will be such that shear failure at a backfill-rock interface will involve shearing through the backfill rather along the backfill-rock interface itself. The shear stress indicated the integrity of the backfill and the surrounding rock in the condition of interaction.

Figures 14(a)-14(c) show the shear stress of the numerical monitoring points at the same height $(Y=0)$ in these three models. On the linear boundary model, the monitoring point-S11 represented the internal rock, the point-S4 represented the boundary rock, point-B4 represented the boundary backfill, and the point-B11 represented the internal backfill (as shown in Figure 10). The same corresponding relationship existed in the other two models. The shear stress of the backfill increased in the complex boundary model. The peak shear stress of the backfill in the linear boundary model was $0.3 \mathrm{MPa}$, the peak shear stress of the backfill in the single-step boundary model was $2.53 \mathrm{MPa}$, and the peak shear stress of the backfill in the multistep boundary model was $4.80 \mathrm{MPa}$.

The difference of shear stress in the surrounding rock and backfill was decreased as the complexity of the model boundary increased. For the multistep boundary model, the curves of shear stress of the backfill and the surrounding rock nearly 
coincided. The similar trend and shape indicated that the integrity of the contact zone for the multistep boundary model was better than the integrity of the zones for the other two types of boundaries. The boundary complexity was helpful for local stability of the backfill.

\section{Conclusions}

In this study, we analyzed how the geometric characteristics of the backfill boundary influenced the distribution of stress on the contact zone between the backfill and the surrounding rock. The conclusions of this study are as follows:

(1) For stress distribution, in the deeper part of the backfill boundary, the accumulated horizontal stress was larger than the accumulated vertical stress. In the shallow part of the backfill boundary, the accumulated vertical stress was larger than the accumulated horizontal stress. On the contact zone of the surrounding rock and the backfill (the boundary part of the backfill), both the horizontal stress and vertical accumulated stress of the surrounding rock were both larger than those of the backfill.

(2) The degree of complexity had an effect on the stress transference and the interaction between the surrounding rock and the backfill on the contact zone, which influenced the local stability of the backfill boundary.

(3) The change in the direction of the stress vectors was the largest on the multistep boundary model, and the change in the direction of the stress vectors was the smallest on the linear boundary model. Therefore, the boundary geometric contributed to the change in the stress direction.

(4) The integrity of the contact zone for the multistep boundary model was better than the integrity of the zones for the other two types of boundary models. The boundary complexity was helpful for the local stability of the backfill.

\section{Data Availability}

The data used to support the findings of this study are included within the article.

\section{Conflicts of Interest}

The authors declare that they have no conflicts of interest.

\section{Acknowledgments}

This research was funded by the project of National Natural Science Foundation titled "Research of failure mechanism about vertical shaft deformation in condition of movement in metal mine," grant nos. 41831293, 41772341, and 41877274 .

\section{References}

[1] T. Belem and M. Benzaazoua, "Design and application of underground mine paste backfill technology," Geotechnical \& Geological Engineering, vol. 26, no. 2, pp. 147-174, 2008.

[2] M. Raynal, J. F. Laurens, and R. AndréJehan, "In situ tests on backfilling and surrounding host-rock in the case of a radioactive waste disposal in a layered salt formation," Engineering Geology, vol. 34, no. 3-4, pp. 281-293, 1993.

[3] L. Quansheng, L. Dongfeng, T. Yongchao, and X. Liu, "Numerical simulation of stress-strain behaviour of cemented paste backfill in triaxial compression," Engineering Geology, vol. 231, pp. 165-175, 2017.

[4] M. Fahey, M. Helinski, and A. Fourie, "Development of specimen curing procedures that account for the influence of effective stress during curing on the strength of cemented mine backfill," Geotechnical \& Geological Engineering, vol. 29, no. 5, pp. 709-723, 2011.

[5] J. R. Barret, M. A. Coulthard, and P. M. Dight, "Determination of fill stability mining with backfill," in Proceedings of the 12th Canadian Rock Mechanics Symposium, Canadian Institute of Mining and Metallurgy, Sudbury, Ontario, Canada, May 1978.

[6] P. J. Bourne-Webb, D. M. Potts, D. König, and D. Rowbottom, "Analysis of model sheet pile walls with plastic hinges," Géotechnique, vol. 61, no. 6, pp. 487-499, 2011.

[7] C. Duan, C. Yan, B. Xu et al., "Crosshole seismic CT data field experiments and interpretation for karst caves in deep foundations," The Engineering Geologist, vol. 228, pp. 188-196, 2017.

[8] M. Fall and M. Pokharel, "Coupled effects of sulphate and temperature on the strength development of cemented tailings backfills: portland cement-paste backfill," Cement and Concrete Composites, vol. 32, no. 10, pp. 819-828, 2010.

[9] M. Fall and S. S. Samb, "Influence of curing temperature on strength, deformation behaviour and pore structure of cemented paste backfill at early ages," Construction and Building Materials, vol. 305, pp. 125-135, 2006.

[10] M. Fall and S. S. Samb, "Pore structure of cemented tailings materials under natural or accidental thermal loads," Materials Characterization, vol. 59, no. 5, pp. 598-605, 2008.

[11] M. Fall and M. Benzaazoua, "Modeling the effect of sulphate on strength development of paste backfill and binder mixture optimization," Cement and Concrete Research, vol. 35, no. 2, pp. 301-314, 2005.

[12] N. Sivakugan, R. M. Rankine, K. J. Rankine, and K. S. Rankine, "Geotechnical considerations in mine backfilling in Australia," Journal of Cleaner Production, vol. 4, no. 12-13, pp. 1168-1175, 2006.

[13] O. Nasir and M. Fall, "Shear behaviour of cemented pastefillrock interfaces," Engineering Geology, vol. 101, no. 3-4, pp. 146-153, 2008.

[14] K. Fang and M. Fall, "Effects of curing temperature on shear behaviour of cemented paste backfill-rock interface," International Journal of Rock Mechanics and Mining Sciences, vol. 112, pp. 184-192, 2018.

[15] E. Yilmaz, T. Belem, B. Bussière, M. Mbonimpa, and M. Benzaazoua, "Curing time effect on consolidation behaviour of cemented paste backfill containing different cement types and contents," Construction and Building Materials, vol. 75, pp. 99-111, 2015. 
[16] C. Liang and M. Fall, "An evolutive elasto-plastic model for cemented paste backfill," Computers and Geotechnics, vol. 71, pp. 19-29, 2016.

[17] M. Pokharel and M. Fall, "Combined influence of sulphate and temperature on the saturated hydraulic conductivity of hardened cemented paste backfill," Cement and Concrete Composites, vol. 38, pp. 21-28, 2013.

[18] J.-K. Kim, Y.-H. Moon, and S.-H. Eo, “Compressive strength development of concrete with different curing time and temperature," Cement and Concrete Research, vol. 28, no. 12, pp. 1761-1773, 1998.

[19] U. Schneider, "Concrete at high temperatures-a general review," Fire Safety Journal, vol. 13, no. 1, pp. 55-68, 1988.

[20] Q. Chongchong, C. Qiuson, A. Fourie et al., "Constitutive modelling of cemented paste backfill: a data-mining approach," Construction and Building Materials, vol. 197, pp. 262-270, 2019.

[21] F. Cihanhir, B. Ercikdi, A. Kesimal, H. Deveci, and F. Erdemir, "Paste backfill of high-sulphide mill tailings using alkali-activated blast furnace slag: effect of activator nature, concentration and slag properties," Minerals Engineering, vol. 83, pp. 117-127, 2015.

[22] C. Qi, A. Fourie, Q. Chen et al., "Neural network and particle swarm optimization for predicting the unconfined compressive strength of cemented paste backfill," Construction and Building Materials, vol. 159, pp. 473-478, 2018.

[23] B. D. Thompson, W. F. Bawden, and M. W. Grabinsky, "In situ measurements of cemented paste backfill at the Cayeli Mine," Canadian Geotechnical Journal, vol. 49, no. 7, pp. 755-772, 2012.

[24] D. O. Potyondy and P. A. Cundall, "A bonded-particle model for rock," International Journal of Rock Mechanics and Mining Sciences, vol. 41, no. 8, pp. 1329-1364, 2004.

[25] E. Yilmaz, T. Belem, and M. Benzaazoua, "Effects of curing and stress conditions on hydromechanical, geotechnical and geochemical properties of cemented paste backfill," Engineering Geology, vol. 168, pp. 23-37, 2014.

[26] M. Helinski, A. Fourie, M. Fahey, and M. Ismail, "Assessment of the self-desiccation process in cemented mine backfills," Canadian Geotechnical Journal, vol. 44, no. 10, pp. 1148-1156, 2007.

[27] M. Helinski, M. Fahey, and A. Fourie, "Numerical modeling of cemented mine backfill deposition," Journal of Geotechnical and Geoenvironmental Engineering, vol. 133, no. 10, pp. 1308-1319, 2007.

[28] M. Helinski, M. Fahey, and A. Fourie, "Coupled two-dimensional finite element modelling of mine backfilling with cemented tailings," Canadian Geotechnical Journal, vol. 47, no. 11, pp. 1187-1200, 2010.

[29] K. Le Roux, W. F. Bawden, and M. Grabinsky, "Field properties of cemented paste backfill at the Golden Giant Mine," in Proceedings of the 8th International Symposium on Mining with Backfill, pp. 233-241, Beijing, China, September 2013.

[30] T. J. Williams, D. K. Denton, M. K. Larson et al., "Geomechanics of reinforced cemented backfill in an underground stope at the Lucky Friday Mine," Report of Investigations, vol. 138, pp. 1-16, 2001.

[31] E. Yilmaz, A. Kesimal, and B. Ercidi, "Strength development of paste backfill simples at long term using different binders," in Proceedings of 8th symposium Mine Fill04, pp. 281-285, Beijing, China, September 2004.

[32] M. Fall, M. Benzaazoua, and S. Ouellet, "Experimental characterization of the influence of tailings fineness and density on the quality of cemented paste backfill," Minerals Engineering, vol. 18, no. 1, pp. 41-44, 2005.

[33] M. Helinski, A. B. Fourie, and M. Fahey, "Mechanics of early age cemented paste backfill," in Proceedings 9th International Seminar on Paste and Thickened Tailings, pp. 313-322, Australian Centre of Geomechanics, Perth, Australia, April 2006.

[34] M. Fall, T. Belem, S. Samb, and M. Benzaazoua, "Experimental characterization of the stress-strain behaviour of cemented paste backfill in compression," Journal of Materials Science, vol. 42, no. 11, pp. 3914-3922, 2007.

[35] L. Rong, M. Fengshan, Z. Jie, W. Jianbo, L. Guilin, and D. Bing, "Monitoring and analysis of stress and deformation features of boundary part of backfill in metal mine," Sustainability, vol. 12, no. 2, pp. 1-14, 2020.

[36] L. Rong, M. Fengshan, G. Jie, and Z. Haijun, "Monitoring and analysis of ground subsidence and backfill stress distribution in Jinchuan Mine, China," Current Science, vol. 115, no. 10, pp. 1970-1977, 2018.

[37] T. Liu and C. Zhou, "Characteristics of in-situ stress state and control methods of ground pressure in Jinchuan nickel mine," Rock and Soil Mechanics, vol. 18, pp. 30-33, 1997.

[38] B. Tikov and B. Mostafa, "Design and application of underground mine paste backfill technology," Geotechnical \& Geological Engineering, vol. 26, pp. 147-174, 2008.

[39] D. Marcial, P. Delage, and Y. J. Cui, "On the high stress compression of bentonites," Canadian Geotechnical Journal, vol. 39, no. 4, pp. 812-820, 2002. 